\title{
Design, Modeling and Virtual Validation of Mobility platform of Tracked Vehicle
}

\author{
Syed Talat Shabbir and Chen Hui-yan \\ School of Mechanical and Vehicular Engineering Beijing Institute of Technology, Beijing, 100081, China
}

\begin{abstract}
Hull design of a tracked vehicle plays a critical role in the vehicle mobility, crew protection and combat performance. This work is intended to design a hull of 50 Ton tracked vehicle using conventional layout of suspension and running gear components. Driver compartment of hull is designed based upon driver height of $1.69 \mathrm{~m}$. Critical hull parameters such as angle of departure, location of 1st road wheel w.r.t idler wheel, location of last road wheel w.r.t sprocket and distribution of middle road wheels are calculated. Finally, designed hull is modeled in Pro/Engineer software and Recurdyn software is used to ascertain vehicle performance in various prototype tests. In the wake of scarcity of papers on this subject, this paper not only outlines the process of hull design for conventional tracked vehicles but also for unconventional ones such as autonomous tracked vehicles.
\end{abstract}

\section{Introduction}

The mobile platform of the tracked vehicle, which can carry the turret with or without gun, is called as the hull of a tracked vehicle. This platform or hull ensures high mobility and protection in combat condition. Three main characteristic of the tracked vehicle are fire power, mobility and protection [1]. The hull of tracked vehicle has very high relation to the mobility and reasonable relation to the protection. The purpose of this study is to design a mobility platform of a tracked vehicle and to investigate its performance prior to field testing. In the course of design of high speed tracked vehicle, number of field tests are required to analyse the performance of designed vehicle. Development cycle based upon field testing is long and cost intensive. Therefore, mathematical design and simulation process is adopted for initial design calculations of mobility platform of 50 Ton tracked vehicle. Designed mobility platform is investigated by using multibody dynamic simulation in Recurdyn program.

\section{Hull design}

\subsection{Height of the hull}

In Asian standard a driver's compartment with a height of $900-1000 \mathrm{~mm}$ and a suitably designed seat a man can be easily accommodated in the compartment. This information is from the ergonomic study of a man and experience [2]. We cannot play much with this height or increase it to our desire since it effects the overall height of the tracked vehicle.

\subsection{Length of the hull.}

Again the ergonomic studies on tracked vehicles and practical experience indicates that the driver should have some suitable distance at his disposal for his body and controls. Here the height of the man considered is $1.69 \mathrm{~m}$ tall. Including the protection thickness of the front nose gives the length from front to the driver's compartment.

\subsection{Width of the hull}

The width of the tracked vehicle would be restricted by the railway carriages and the transporters to be used for the tracked vehicles. The performance or steerability would also be effected by too wide or too narrow tracked vehicle. As an experience the hull width is generally kept up to 2 meters. This would end up with the tracked vehicle width up to $3.5 \mathrm{~m}$.

\subsection{Design of hull profile.}

Following steps indicate the procedure for hull profile design. First we draw a line to indicate the ground. Next draw a reference line $470 \mathrm{~mm}$ higher from the ground line to represent ground clearance. Now draw a line at a height of $990 \mathrm{~mm}$ to represent driver's compartment. Draw another horizontal line in the front at a height of 0.85 meters which is the required vertical obstacle crossing capability of the tracked vehicle. Now place the nose tip at the $0.85 \mathrm{~m}$ high line. If it is lower the tracked vehicle will have difficulty in negotiating vertical obstacles. Idler wheel position is determined on the basis of the required angle of approach for the tracked vehicle. Draw a line at $8^{\circ}$ from the tip backward to mark the 
profile of the top plate cutting the 990-mm height. Angle of $8^{\circ}$ is the angle with the nose armour. If it is reduced the blind zone of the driver would increase.

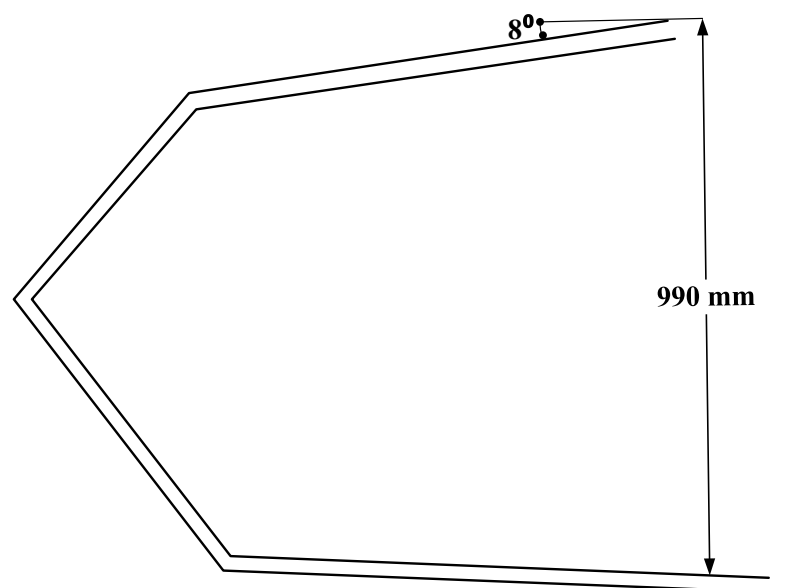

Figure 1. Frontal profile of hull

\subsection{Layout of chassis/Hull.}

In designing running gear arrangement of a tracked vehicle, the critical parameters considered are location of 1 st road wheel w.r.t idler wheel, location of 6th road wheel w.r.t sprocket, angle of approach, angle of departure and distribution of middle road wheels. The angle of approach is generally kept between $30-40^{\circ}$ for modern tracked vehicles. Therefore, the hull is designed to negotiate a slope of $60 \%\left(31^{\circ}\right)$ and vertical obstacle crossing of 0.85 meter. Angle of departure or angle between ground and rear can only be found after determining the position of the sprocket and the last road wheel. The location of the sprocket basically depends on the output of the engine through transmission and final drive. This gives us the starting point and is marked as $O_{1}$ in Fig. 2 where sprocket radius is $R_{z}, R_{w}$ is road wheel radius and $R_{b}$ is radius of balance arm.[3], [4].

$$
O_{1} O_{3}=A_{1}-R_{b}
$$

Refer Fig. 2 to determine distance between center of final drive and torsion bar at sixth road wheel $(A)$

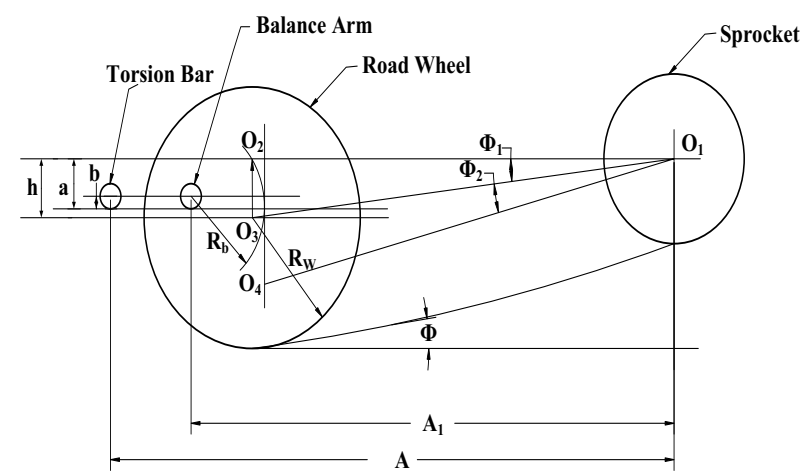

Figure 2. Angle of departure

$$
O_{1} O_{2}=R_{1}+R_{Z}+\delta
$$

$R_{1}=$ vertical distance of shock absorber from bottom; $\delta=$ shock absorber and sprocket clearance (7 10 $\mathrm{mm})$

$$
\begin{gathered}
O_{2} O_{5}=\sqrt{\left(O_{1} O_{2}\right)^{2}-\left(O_{1} O_{5}\right)^{2}} \\
A=O_{2} O_{5}+a_{1}
\end{gathered}
$$

$a_{1}=$ distance of shock absorber center from torsion bar

$$
\phi_{1}=\tan ^{-1} \frac{h}{O_{1} O_{2}}
$$

Now (Fig. 2)

$$
\phi_{2}=\sin ^{-1}\left(\frac{R w-R z}{\sqrt{\left(O_{1} O_{2}\right)^{2}+h^{2}}}\right)
$$

Finally, angle of departure is as under

$$
\phi=\phi_{1}+\phi_{2}
$$

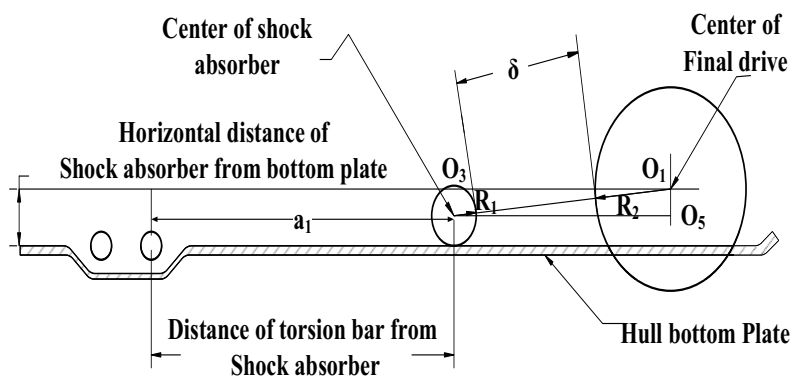

Figure 3. Layout of torsion bar, shock absorber and Final drive

Location of the first road wheel is calculated with respect to idler wheel by keeping the angle of approach as $35^{\circ}$ as shown in Fig. 4.

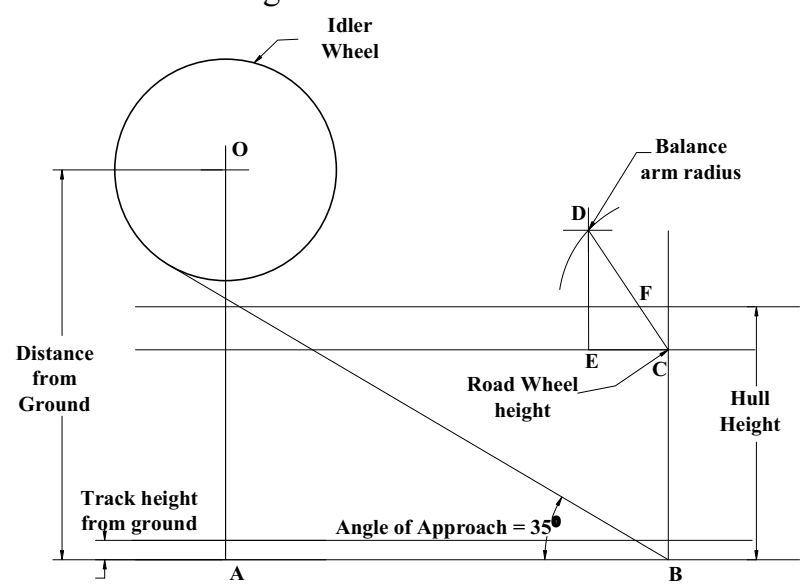

Figure 4. Location of 1st road wheel from Idler

Between the sixth and the first road wheel we can now distribute the other 4 road wheels. Before doing the distribution, it is essential to determine the distance between the two torsion bars. The procedure to be adopted is for worst condition at maximum travel of 
wheel no 6 in upward direction. $D_{1} D_{2}$ is the distance between two road wheels which is calculated from the dimensions given in Fig. 5. $D_{1} D_{2}$ is also the minimum between other road wheels for which allowance is added according to the space requirement for suspension system.

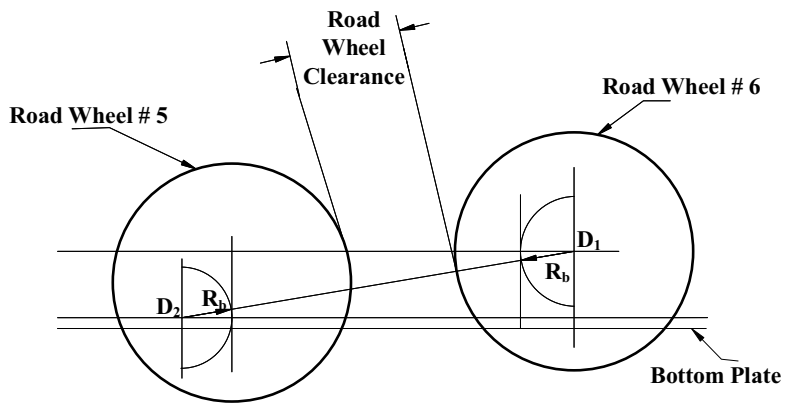

Figure 5. Distance between road wheels

Calculation of layout parameters of hull are summarized in Table-1.

Table 1. Summary of Hull critical parameters.

\begin{tabular}{|c|c|c|}
\hline S/No & \multicolumn{2}{|c|}{ Critical Hull Parameter } \\
\hline 1 & Distance b/w Wheels 1-2 & 850 \\
\hline 2. & $2-3$ & 890 \\
\hline 3. & $3-4$ & 890 \\
\hline 4 & $4-5$ & 890 \\
\hline 5 & $5-6$ & 882 \\
\hline 6. & $\begin{array}{c}\text { Location of 1st Rd wheel } \\
\text { w.r.t Idler wheel (mm) }\end{array}$ & 600 \\
\hline 7. & $\begin{array}{c}\text { Location of 6th rd wheel } \\
\text { w.r.t Final drive (mm) }\end{array}$ & 1038 \\
\hline 8 & Angle of approach & $35^{\circ}$ \\
\hline 9. & Angle of departure & $22.2^{\circ}$ \\
\hline
\end{tabular}

\subsection{Hull modeling}

As per the design process outlined in previous section, hull is modeled in Pro/Engineer software [5,6] which is best suited for parametric modeling. Designed hull exhibits 3 rotational and 3 translation DOF. Ride (pitch and bounce) and handling (yaw, sides slip and roll) characteristics of tracked vehicle are highly dependent on the design layout hull of tracked vehicle. If these motions are controlled the platform is considered to be stabilized. 3D CAD model of designed hull is shown in Fig. 6.

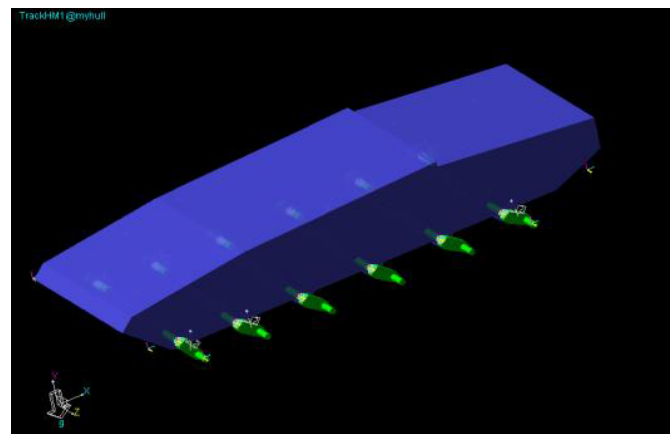

Figure 6. CAD model of hull of tracked vehicle

\section{Virtual prototyping}

Virtual prototype of tracked vehicle $[7,8]$ is built to perform field test prior to design finalization. These tests are costly and often dangerous when conducted on real prototype. In order to construct a virtual model of tracked vehicle we used two software namely Recurdyn and Matlab. 3D designed CAD model is imported in Recurdyn to add suspension and running gear components. Matlab is used to calculate design parameters such as suspension stiffness, damping ratio, etc. Random road profile is also generated in Matlab which is later used in Recurdyn to construct 3D road surface as shown in Fig. 7.

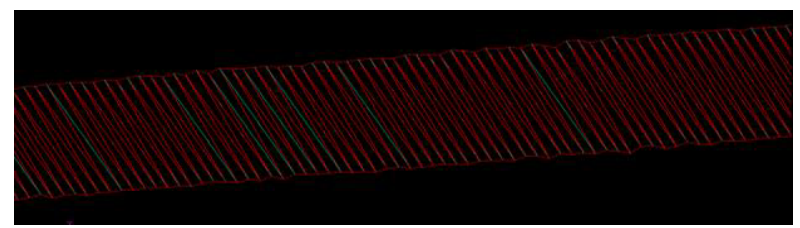

Figure 7. Random road surface

Balance arms, road wheels, sprocket, idler wheels are added to hull using revolute joints. A real damper curve is added to represent non-linear behaviour of damper. A "sphere-cylinder" connection is also used [9] to represent hydraulic limiter to restrain vertical motion of road wheel.

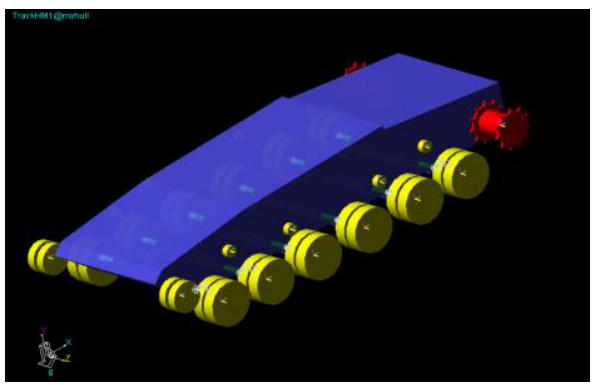

Figure 8. Assembled tracked vehicle without track

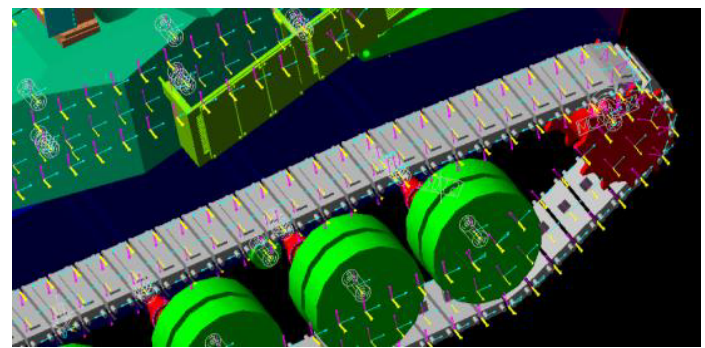

Figure 9. Assembled tracked vehicle with track

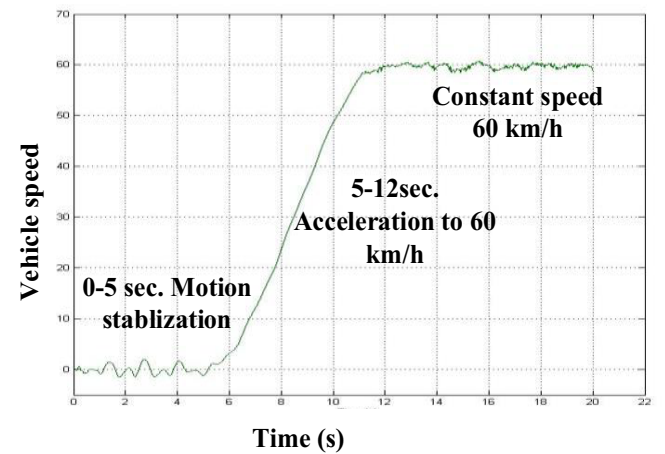

Figure 10. Motion Input curve 


\subsection{Motion input}

Motion input is given at revolute joints provided on sprockets. Step input relation is used to represent tracked vehicle acceleration from 0 to $60 \mathrm{~km} / \mathrm{h}$ in 12 seconds. Vehicle speed curve is shown in Fig. 10.

\section{Results}

Various real field tests were conducted in Recurdyn software to ascertain the performance of designed hull for tracked vehicle. These tests include ditch crossing, slope negotiation and high speed run on a road surface having random profile. All these tests completed successfully and vehicle validated the design process prior to assembling a real prototype.

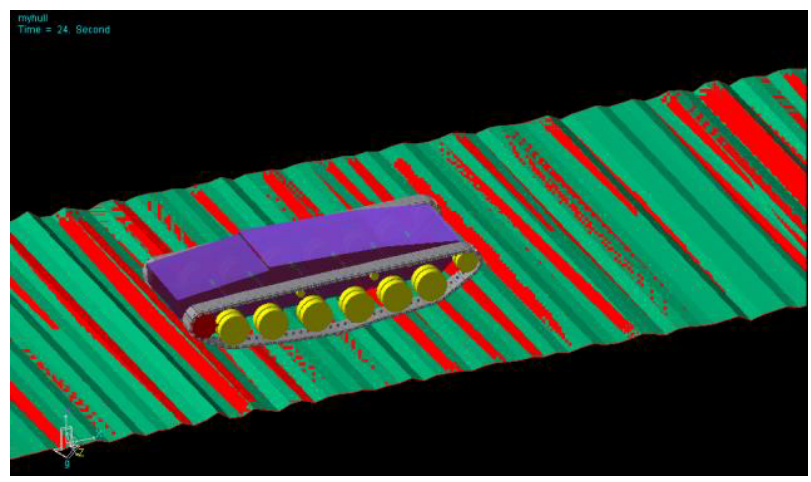

Figure 11. Tracked vehicle over rough terrain

\section{Conclusion}

In the wake of scarcity of papers on the design of tracked vehicle, a complete design process for the hull of tracked vehicle is outlined. Virtual testing of prototype validated the design process and it is inferred that simulation completed successfully and designed tracked vehicle passed prototype testing such as high speed run, trench and obstacle crossing. Design process can be further extended for selection and optimization of suspension and running gear components for different hull layouts.

\section{Acknowledgement}

We gratefully acknowledge to NORINCO China (HITNORINCO PhD Scholarship 2013-17) and Vehicle Laboratory of Beijing Institute of technology, Beijing for provisioning the technical support and bearing the financial effects of our whole research and in particular for this work.

\section{References}

1. National Research Council Canada, Armour Combat Vehicle Mobility Development Study, (Phase 2 Report, 5 July 1999), 29-49.

2. Richard Ogorkiewicz, Technology of Tracked vehicles II, Jane's Information Group Ltd, (1991)

3. Christian Guenther and Cornelius Leondes. Synthesis of a high-speed tracked vehicle suspension system - part I: Problem statement, suspension structure, and decomposition. IEEE. 22: 158-165, April (1977).

4. Murakami M, Watanabe $\mathrm{K}$ and Kitano. A mathematical model for spatial motion of tracked vehicles on soft ground. Journal of Terramechanics, 29(1) :71-81, (1992).

5. Zi-Yue, Ya-Dong GAO et al. Modeling and Simulation of tracked vehicle based on Pro/E and RecurDyn. 5th International Conference on Advanced Design and Manufacturing Engineering, (2015).

6. ChangLiang Cai, Simulation of the tracked duct cleaning robot based on Pro/E and RecurDyn[J], Manufacturing automation, (11):53-56, (2014).

7. Yin Huabing, Hu Licheng, Zhang Zhongsheng, Huang Yingxin. Modeling and simulation of virtual prototype for tracked vehicle with hydro-pneumatic suspension system. 6th Int. Conf. on System Simulation and Scientific Computing (Beijing). Oct. 24-27. (2005)

8. C. Q. Ma, X. X. Liu, B. Q. Dai, "Research and Design of Mechanical System Virtual Prototyping", Applied Mechanics and Materials, 52-54, pp. 624629, (2011)

9. RuiQiang and Wang Hongyan. Multi-body dynamic simulation and experimental validation of high-speed tracked vehicle. Proceedings of the 7th ICFDM 2006 International Conference on Frontiers of Design and Manufacturing, Guangzhou, China, pp: 31-34, June 19-22, (2006). 